\title{
University Education in Human Nutrition: The Italian Experience-A Position Paper of the Italian Society of Human Nutrition
}

\author{
Luca Scalfi, Furio Brighenti, Nino Carlo Battistini, Alessandra Bordoni, \\ Alessandro Casini, Salvatore Ciappellano, Daniele Del Rio, Francesca Scazzina, \\ Fabio Galvano, and Nicolò Merendino
}

The Working Group on Education in Human Nutrition, The Italian Society of Human Nutrition (SINU), Italy

Correspondence should be addressed to Luca Scalfi; scalfi@unina.it

Received 2 March 2015; Accepted 5 May 2015

Academic Editor: Martin Kohlmeier

Copyright (C) 2015 Luca Scalfi et al. This is an open access article distributed under the Creative Commons Attribution License, which permits unrestricted use, distribution, and reproduction in any medium, provided the original work is properly cited.

As a broad range of professionals in clinical and nonclinical settings requires some expertise in human nutrition, the university system must offer academic courses tailored to these different specific needs. In the Italian university system there is still uncertainty with regard to the learning objectives regarding human nutrition. In the ministerial decrees defining the criteria for establishing university courses, the indications about education in human nutrition are rather inconsistent, sometimes detailed, but often just mentioned or even only implied. Education in human nutrition requires both an appropriate duration (number of university credits included in the degree format for different disciplines) and course units that are designed in order to achieve specific expertise. The university system should appropriately design and distinguish the nutritional competencies of the different types of graduates. Physiology and biochemistry are the academic disciplines mostly involved in teaching fundamentals of human nutrition, while the discipline sciences of applied nutrition and dietetics more strictly focuses on applied nutrition and clinical nutrition. Other academic disciplines that may contribute to education in human nutrition, depending on the type of degree, are internal medicine (and its subspecialties), hygiene, endocrinology, food technologies, food chemistry, commodity science, and so forth.

\section{Introduction}

The aim of this document, prepared by a group of experts on behalf of the Italian Society of Human Nutrition (SINU), is to present an opinion on education in human nutrition, as accessible in the Italian university system in first-cycle (first-level) and second cycle (second-level) degrees. Further position papers are needed to define in detail the indications for each of the degrees considered with respect to format, learning objectives, and learning outcomes.

The Italian university system includes first-cycle degrees (Degree, Laurea, L) and second-cycle degrees (Magister Degree, Laurea Magistrale, LM) and thereafter advanced training courses, masters, specialization courses, and Ph.D.'s [1]. The overall purpose is to give students the opportunity to acquire a specific cultural, scientific, and professional profile by achieving different academic diplomas. University education has been progressively adapting to the concepts proposed by the Qualification Framework for the European Higher Education Area [2] and the Italian Qualification Framework for the Higher Education [1], with the latter defining the learning outcomes of the Italian first-cycle degree courses and second-cycle degree courses.

First-Cycle. Qualifications that signify completion of the first cycle are awarded to students who

have demonstrated knowledge and understanding of a field of study that builds upon their general secondary education and is typically at a level that, 
whilst supported by advanced textbooks, includes some aspects that will be informed by knowledge of the forefront of their field of study;

can apply their knowledge and understanding in a manner that indicates a professional approach to their work or vocation and have competencies typically demonstrated through devising and sustaining arguments and solving problems within their field of study;

have the ability to gather and interpret relevant data (usually within their field of study) to inform judgments that include reflection on relevant social, scientific, or ethical issues;

can communicate information, ideas, problems, and solutions to both specialist and nonspecialist audiences;

have developed those learning skills that are necessary for them to continue to undertake further study with a high level of autonomy.

Second-Cycle. Qualifications that signify completion of the second cycle are awarded to students who

have demonstrated knowledge and understanding that is founded upon and extends and/or enhances that typically associated with the first cycle and that provides a basis or opportunity for originality in developing and/or applying ideas, often within a research context;

can apply their knowledge and understanding and problem solving abilities in new or unfamiliar environments within broader (or multidisciplinary) contexts related to their field of study;

have the ability to integrate knowledge and handle complexity and formulate judgments with incomplete or limited information but that include reflecting on social and ethical responsibilities linked to the application of their knowledge and judgments;

can communicate their conclusions and the knowledge and rationale underpinning these to specialist and nonspecialist audiences clearly and unambiguously;

have the learning skills to allow them to continue to study in a manner that may be largely self-directed or autonomous.

These frameworks can be used to evaluate the quality of academic courses and provide a better understanding of the relationships between learning process and knowledge, skills, and competencies. More specifically, the European Qualification Framework (EQF) for lifelong learning [3] focuses on the learning outcomes using an eight-level reference system: the Italian first-cycle degrees and second-cycle degrees correspond, respectively, to level 6 and level 7.

\section{Establishment of Degree Courses in Italy}

The ministerial decrees $[4,5]$ provide definition and characteristics of 43 types (referred to as classes) of first-cycle degrees (L/1 to L/43) and 94 second-cycle degrees (LM/1 to $\mathrm{LM} / 94)$. There are, in addition, 4 classes of first-cycle degrees and 4 classes of second-cycle degrees for healthrelated professions $[6,7]$ and also a small number of singlecycle degrees such as medicine, dentistry, and pharmacy.

The ministerial decrees [4-7] indicate the educational objectives and the fundamental learning activities for each type of degree. In addition, they provide an outline of professional objectives and potential employment opportunities. For each degree the learning activities, expressed as university credits, are partitioned according to different subject areas, with each of which including several academic disciplines (defined as SSD, Settori Scientifico-Disciplinari). The total number of expected university credits is 180 for first-cycle degrees, 120 for second-cycle degrees, and 240 or 300 for single-cycle degrees (60 university credits per year).

The courses established by each university have their own format and unit program. Each university chooses the academic disciplines to be included in the academic course among those listed in the ministerial decrees. An academic discipline can, therefore, provide no course unit or one or more units, with a variable number of university credits. The academic courses that belong to the same type of degree share the same educational objectives and confer equal legal qualification but can differ greatly in their teaching contents.

\section{Education in Human Nutrition}

Human nutrition, as a body of knowledge, skills, competence, and professional activities, is an interdisciplinary area covering chemical, molecular, genetic, biochemical, physiological, psychological, cognitive-behavioural, statisticalepidemiological, clinical, food-related, technological, educational, economic, political, and social aspects.

The following paragraphs focus on the university degrees for which education in nutrition is essential (Table 1), with the aim to identify and analyse the role of human nutrition in relation to the learning objectives set out by the ministry, the learning paths of the degree, and the professional profiles.

Two degrees are specifically related to human nutrition: a first-cycle degree in dietetics and nutrition and a secondcycle degree in nutrition sciences. Other academic fields considered are food science and technologies, biological sciences, pharmaceutical sciences, medical sciences, and sport sciences.

3.1. Food Science and Technologies. Human nutrition is a key subject in the field of food sciences and technologies, particularly with regard to food quality and nutritional characteristics of foods; nutrition labelling and health claims; design of novel foods and foods for special medical purposes; catering; industry's role in improving the nutritional quality of foods. The relationship between food science and technologies and human nutrition also emerges by considering food-based dietary guidelines or legislation on foodstuffs, as 
TABLE 1: First-cycle and second-cycle Italian university degrees in which education in human nutrition is essential or very useful.

\begin{tabular}{lll}
\hline & & \multicolumn{1}{c}{ First-cycle degrees (L) } \\
\hline L-2 & Biotecnologie & Biotechnology science \\
L-13 & Scienze Biologiche & Biological sciences \\
L-22 & Scienze Delle Attività Motorie e Sportive & Science of physical activity and sport \\
L-26 & Scienze e Tecnologie Alimentari & Food science and technologies \\
L-29 & Scienze e Tecnologie Farmaceutiche & Pharmaceutical sciences and technologies \\
L/SNT3 & Laurea in Professioni Sanitarie Tecniche-Dietista & Technical health professions-dietitian \\
L/SNT1 & Professioni Sanitarie Infermieristiche e & Health care nursing professions and \\
& Professione Sanitaria Ostetrica & healthcare obstetric profession \\
\hline LM-6 & \multicolumn{1}{c}{ Second-cycle degrees (LM) } \\
LM-7 & Biologia & Biology \\
LM-13 & Biotecnologie Agrarie & Agricultural biotechnology \\
LM-41 & Farmacia e Farmacia Industriale & Pharmacy and Industrial pharmacy \\
LM-61 & Medicina e Chirurgia & Medicine (single-cycle degree) \\
LM-67 & Scienze Della Nutrizione Umana & Science of human nutrition \\
LM-68 & Scienze e Tecniche Delle Attività Motorie & Sciences and techniques of preventive \\
LM-70 & Preventive e Adattate & and adaptive physical activity
\end{tabular}

L: Laurea (degree); LM: Laurea Magistrale (magister degree).

well as numerous scientific publications in journals of the ISI categories Nutrition and Dietetics and Food Science and Technologies. In addition, there are several research units on human nutrition in university departments and research institutions of food science and technologies.

The ministerial decrees $[4,5]$ define in Italy a first-cycle degree $\mathrm{L} / 26$ (food science and technologies) and a second-cycle degree LM/70 (food science and technologies). The learning objectives related to human nutrition for the degree L/26 are ensuring nutritional quality of foods; use of diet for promoting health; implementation and supervision of food catering; assessment of dietary habits. Further indications for the degree LM/70 are management and promotion of food quality and safety and highly specialised skills for quality control and food safety. Biochemistry, physiology, science of applied nutrition, food chemistry, and hygiene are the scientific disciplines which may be involved in the education in human nutrition.

3.1.1. Professional Profile. Food technologists are involved in the production, processing, and distribution of food products and in the related activities of analysis, inspection, certification, and so forth, as well as in quality improvement and promotion of food products. In addition, they work in the catering industry, the retail distribution industry, and the agritourisms. Food technologists may collaborate in nutritional consulting, planning of menu, and research and development in the area of applied nutrition.

3.1.2. Comments. Course units related to human nutrition are found in many, but not all, academic courses in food science and technologies, including those focusing on catering or food and wine industry.

As far as education in human nutrition is concerned, in addition to the physiological role of nutrients other issues of particular interest are laboratory analyses related to the nutritional quality of food products (raw or processed), nutritional characteristics of the food groups, and changes due to food processing, design of novel foods, assessment of food habits, nutrition labelling, and educational tools. For catering and the food and wine industry, skills are required with regard to applied nutrition and public health nutrition. Cross competencies with areas such as food technology and food microbiology are also of particular interest.

3.2. Biological Sciences. Since nutrients and food components have a major role in biological processes from the molecular level to the whole organism, not surprisingly, biologists are usually involved in laboratory research on nutrition, as well as in the evaluation of nutritional status.

In this academic field there are a first-cycle degree $\mathrm{L} / 13$ (biological sciences) and an interrelated second-cycle degree LM/6 (biology) $[4,5]$. The degree L/13 highlights the need for a basic as well as for a job-oriented education, whereas the degree LM/6 aims at teaching more specific aspects of biology, in the presence of an academic learning path (among others) focused on human nutrition. The scientific disciplines involved in education in human nutrition are in particular biochemistry, physiology, science of applied nutrition, and hygiene.

3.2.1. Professional Profile. As advanced professional expertise (also according to a formal opinion of the Italian National 
Health Board), the registration as biologist provides the legal qualification for evaluating nutritional status and assessing nutritional needs and to plan optimal diets. Biologists with specific interest in human nutrition are involved in laboratory evaluation of food safety and quality, assessment of nutritional status and diet adequacy, nutritional counselling, planning of diet for individuals and communities, and promotion of healthy foods.

3.2.2. Comments. In Italy education in human nutrition is not usually considered among the learning objectives of the university courses in biological sciences and is therefore not taken into consideration in their unit programs. Instead, universities should evaluate the opportunity to activate personalised paths aimed at attaining more specific competencies in human nutrition.

Education in human nutrition provides competencies that are often essential to the biologists. All students should be guaranteeing the chance to improve their own nutritional skills. At least the fundamentals of nutritional biochemistry and physiology should be taught in the degree L/13, together with a general overview on metabolism. In the degree LM/6, if the aim is in an in-depth teaching on human nutrition, attention must be paid to nutrition in physiological and pathological conditions.

3.3. Dietetics and Nutrition. Public health nutrition and clinical nutrition are major topics in the field of dietetics and nutrition. Dietitians are usually involved in research in this area.

The first-cycle degree L/SNT-3 (health professionsdietitian) aims at achieving both knowledge and technical/ practical skills and competencies [6]. Education in human nutrition involves scientific disciplines such as physiology, biochemistry, sciences of applied nutrition, hygiene, food science and technologies, food chemistry, and commodity science. In addition, clinical disciplines examine the role of human nutrition in the prevention and treatment of acute and chronic diseases. The format of academic courses also offers activities of practice and internship.

3.3.1. Professional Profile. The professional role of the dietitian is clearly recognized. According to the ministerial decree [6], dietitians work in private practices, community organizations, and medical settings. Dietitians organize and coordinate specific activities related to applied nutrition and clinical nutrition; they cooperate in the control of food safety; they plan diets (prescribed by a physician) and are involved in the dietary treatment of patients; they cooperate with other professionals in the treatments of eating disorders; they organize catering for communities; they carry out activities related to nutritional education. In addition, the dietitian may play a key role in research, especially in the assessment of the nutritional status.

3.3.2. Comments. The courses in dietetics and nutrition should guarantee a balanced approach to knowledge and activities of practice. Understanding the fundamentals of human nutrition ensures a correct approach to applied nutrition and clinical nutrition, while clinical teachings should be oriented towards the role of human nutrition in both prevention and therapy. The internship sets a connection between advanced skills and competencies at a higher level. Finally, interpersonal and communication skills with healthy subjects or patients are to be considered of great importance.

3.4. Pharmaceutical Sciences. Human nutrition and pharmaceutical sciences both share a strong interest for the effects of food components on health, the healthy impact of food supplements and enriched/fortified foods, and so forth. Research in pharmacology is mostly focused on bioactive molecules found in foods. Journals that synthesise this approach are found in the ISI categories: Nutrition and Dietetics, Pharmacology, Food Science and Technologies and Toxicology.

In Italy, two degrees are related to the academic field of pharmaceutical sciences $[4,5]$ : the first-cycle degree L/29 (pharmaceutical sciences and technologies) and the singlecycle (five years) degree LM/13 (pharmacy and industrial pharmacy). With respect to human nutrition, graduates in L/29 are expected to have competence in the formulation, production, and quality control of nutritional products (including those tailored for specific goals and needs) and nutritional supplements. Graduates in LM/13 may be involved in the development and production of foods for special medical purposes and supplements, as well as in nutritional counselling. Physiology and biochemistry are the disciplines expected to teach the fundamentals of human nutrition, whereas the discipline sciences of applied nutrition is considered among the core disciplines of the degree LM/ 13.

3.4.1. Professional Profile. The graduates in the degree L/29 may carry out the formulation, the production, and the quality control of nutritional products, as well as the inspection and the preparation of supplements. The pharmacists (graduates in the degree LM/13) can operate as specialists of dietetic and herbal products. In addition, they have also been qualified as nutritional counsellors, as attested by the Italian National Health Board. On the other hand, pharmaceutical sales representatives are interested in nutrition with respect to the treatment of metabolic disorders and nutrition-related diseases. Finally, pharmacists play a key role in managing enteral nutrition and in the preparation of parenteral nutrition.

3.4.2. Comments. Human nutrition, with a few exceptions, is not adequately considered in the academic courses of pharmaceutical sciences.

Education in human nutrition is needed in both the firstcycle and the second-cycle Degrees. Skills and competencies of graduates in the degree L/29 are selective. For graduates in the degree LM/13 more advanced competencies are required regarding the use of food supplements, foods for special medical purposes, and enteral nutrition for the treatment of nutrition-related diseases; nutrition education; preparation of parenteral nutrition. 
3.5. Medical Sciences. Nutrition plays a primary role in prevention and therapy of both noncommunicable chronic diseases and other organ-related diseases. Thus, not surprisingly, an impressive number of articles related to human nutrition have been published in the field of medical sciences in categories such as cardiac and cardiovascular systems, gastroenterology, nephrology, and paediatrics.

Indeed, the role of nutrition to promote health in all age groups is very often ignored by the National Health System. For example, obesity and malnutrition are often not identified or considered. This erroneous attitude is reflected also in the learning objectives indicated by the ministerial decree [5] for the degree in medicine (LM/41), which describes the medical profession as a holistic approach to preserve and restore health. Nutrition is not mentioned at all, whereas metabolism is just cited in brief.

Indeed, the disciplines which are possibly involved in the education in human nutrition are biochemistry, physiology, and science of applied nutrition. The role of human nutrition in the prevention and treatment of acute and chronic diseases can also be examined by disciplines such as hygiene, internal medicine, endocrinology, gastroenterology, cardiology, nephrology, and paediatrics.

3.5.1. Professional Profile. With respect to human nutrition, physicians are the only professionals qualified to diagnose nutrition-related diseases and prescribe diets. They should also promote healthy lifestyles (including healthy food habits) in the general population and at-risk groups. In addition, they should also demonstrate an inclination to collaborate with other professionals with competencies in human nutrition.

3.5.2. Comments. Human nutrition, with a very few exceptions, is not considered in the academic courses of medicine. Education in human nutrition has to be always included in the courses of the degree in medicine. Knowledge of metabolism and the nutritional role of food components constitutes an essential scientific background which should be combined with more advanced expertise in nutritional diagnosis and therapy.

Overall, graduates in medicine should attain adequate skills and competencies with respect to relationships among food, nutrition, health, and well-being; nutritional role of food components; nutrient requirements in physiological or pathological conditions; human nutrition in prevention and treatment; nutrition surveillance in the general population; appropriate use of tools for assessing nutritional status; food and nutrition information; basic principles of nutritional therapy; cooperation with other professionals with specific nutritional competencies.

3.6. Sport Sciences. Sport sciences and human nutrition both focus on the optimal nutrition for athletes and the relationship of physical activity with health and wellness. In addition, physical activity plays also a significant role in the treatment of nutrition-related diseases (obesity, diabetes, etc.).

In Italy there are three degrees $[4,5]$ belonging to this academic area: the first-cycle degree L/22 (physical activity and sport) and the subsequent second-cycle degrees LM/67 (sciences and techniques in preventive and adapted physical activity) and LM/68 (sport sciences and techniques). The degree LM/67 focuses on the promotion of healthy lifestyles (including diet) in the general population and the physically disabled, while the education in sports nutrition (i.e., nutrition and physical performances) is mentioned among the learning objectives of the degree LM/68.

3.6.1. Professional Profile. Graduates in sports sciences should be able to plan, organize, and manage physical activity programs and sport activities (also at a competitive level), as well as the activities of developing, preserving, and recovering physical fitness and the related psychophysical well-being. Related professional profiles are educators in the prevention of sedentary lifestyle, overweight, and obesity; educators in adaptive activities aimed at the achievement of physical fitness.

3.6.2. Comments. With respect to education in human nutrition, graduates in sports sciences (especially in the degrees LM/67 and LM/68) are expected to acquire general knowledge of the nutritional role of food components and nutrient requirements and more specific information on sports supplements. Moreover, they must acquire competence in the assessment of body composition, the promotion of a healthy diet as a major component of a healthy lifestyle, and the support in dietary planning for athletes. They should also demonstrate an inclination to collaborate with other professionals with competencies in human nutrition.

3.7. Science of Human Nutrition. The rationale of the secondcycle degree in science of human nutrition (LM/61) can be found in the increasing value recognized to nonclinical areas of human nutrition. The degree in science of human nutrition is not directly related to any first-cycle degree [5]. Students usually come from areas such as dietetics and human nutrition, biological sciences, food sciences and technologies, pharmacy, and biotechnologies. As a consequence, due to this heterogeneity, there could be problems in teaching to students with very different academic careers.

The learning objectives of the degree L/61 aim at the achievement of advanced knowledge, skills, and competencies in the biochemical and nutritional role of nutrients and other substances of nutritional interest; the evaluation of energy and nutrient requirements in individuals and communities; the assessment of nutritional status (laboratory tests and measurements in vivo); the influence of foods and diet on health and well-being; food processing, including functional foods and foods for special medical purposes; food regulation and legislation.

3.7.1. Professional Profile. Because of its own characteristics, the degree in science of human nutrition enriches the professional skills of graduates who have already acquired competencies in different academic fields. Actually, graduates in LM/61 work in different settings such as public health, sports nutrition, the media, food industry, catering industry, education, and research, often collaborating with other professionals with specific nutritional competencies. 
3.7.2. Comments. The courses in science of dietetics and human nutrition have been established in different Italian universities through the cooperation between departments of medicine, biological sciences, food sciences and technologies, pharmacy, biotechnology, and so forth. Actually, they differ to a significant extent with respect to learning objectives, formats, and course unit programmes.

The professional profile is therefore strongly influenced by the curriculum of each student. In general terms, the graduates in LM/61 should attain advanced expertise in laboratory analyses and the evaluation of the nutritional quality of food products (raw or processed); design, production, and distribution of functional foods, foods for special medical purposes, and supplements; use of nutrition claims and health claims; assessment of nutritional status; planning of diet in different physiological and pathological conditions; catering; nutrition education; consultancy in human nutrition. In addition, the achievement of LM/61 enables the registration as biologist (see above).

The primary objective of the degree LM/61 is to give students the opportunity to reach advanced competencies in human nutrition. The course programme has to guarantee the balanced presence of the different scientific and cultural fields related to human nutrition (especially to applied nutrition) as well as of other fields such as biochemistry, statistics, epidemiology, hygiene, food safety, and food technologies. Clinical disciplines are also indispensable to describe both the relationships of food components, foods and diet with health and well-being, and the pathogenesis and treatment of nutrition-related diseases.

3.8. Other Degrees. Education in human nutrition may also be somewhat considered in other degrees such as the degrees in biotechnology $[4,5]$ and those for health professionals $[6$, 7]. Nurses, for example, must acquire expertise in nutritional screening and the management of enteral and parenteral nutrition. On the other hand, professional profiles such as the obstetrician are specifically involved in providing health advice and promoting healthy eating.

\section{Remarks}

As already observed in other countries [8-13], there is still uncertainty in Italy with regard to how and to which extent human nutrition should be taught in the different university degrees. In the ministerial decrees that define the general criteria for establishing university degrees $[4,7]$ indications about education in human nutrition are sometimes detailed, but usually little more than mentioned or even only implied. Human nutrition is the scientific and cultural core of both the first-cycle degree in dietetics and nutrition and the secondcycle degree in sciences of human nutrition and significantly contributes to the learning objectives set for the degree in food science and technologies. In other cases, nutritional aspects are shortly mentioned (pharmacy and industrial pharmacy and sport sciences) or cannot be drawn at all from the learning objectives indicated by the ministerial decrees (biology and medicine).
As previously mentioned, academic courses are organised by each university according to the criteria set by the ministerial decrees. As a consequence, education in human nutrition may be absent also in those courses where it is highly needed. With the exception of the two degrees specifically related to human nutrition, the definition of knowledge, abilities, and competencies tends often to be incomplete and learning objectives regarding human nutrition are frequently overlooked. Finally, there are important differences with respect to education in human nutrition (learning objectives, number of units, etc.) among courses belonging to the same class of degree.

As far as the nutritional training of health professionals is concerned, it should be noted that graduates in dietetics and nutrition at the end of the course take the degree and pass a government exam to be licensed as dietitians. There is no path to reach any further legal qualification similar to that of registered dietitian. In addition, there is a medical specialisation course ( 4 years) in human nutrition and dietetics. Human nutrition may also be taught (in an inconsistent way) in other medical specialisation courses (e.g., in internal medicine or gastroenterology), while biologists may attend the course (4 years) in human nutrition and dietetics (with slightly different learning objectives). Finally, postdoctoral masters in human nutrition and also research doctorates are poorly recognised as legal and professional qualifications for health professionals.

The training programme appears to be sufficient for the degree in human nutrition and dietetics (500-700 graduates per year) and the specialisation course in human nutrition and dietetics (25-30 specialized medical doctors per year), but it is quite absent for medical doctors and other health professionals. Overall, as already reported [14], the national health service is not capable of meeting the needs for public health nutrition and clinical nutrition. Unfortunately, no data are available on how this impacts on both the health of the general population and health care cost and utilisation in Italy.

\section{Position}

Human nutrition is a highly interdisciplinary culturalscientific discipline with a well-defined identity with respect to clinical and nonclinical issues. As a broad range of professionals in different settings requires some expertise in this area, the university system must offer academic courses tailored to specific needs.

In first-cycle and second-cycle academic degrees, the university system must appropriately define the nutritional competencies of the different types of graduates, preserving a reasonable consistency among the university courses belonging to the same type of degree.

Education in human nutrition must be structured according to the learning objectives and expected outcomes of each type of degree; knowledge, skills, and competencies should be clearly defined. Not only should the inputs be taken into consideration (length and characteristics of the learning activities, theoretical contents of the discipline, etc.), but the same should be also said about the actual knowledge 
and skills graduates acquire. The learning objectives of an academic course must be compatible with the expected activities. Teaching should focus first on the nutritional role of nutrients and other substances of nutritional interest and their metabolism and on the relationship of food components and diet with health and well-being. As a further step, the nutritional competencies specific to each type of graduate may be implemented, including those shared with other cultural and scientific fields.

Education in nutrition is interdisciplinary but not fragmentary. It requires both an appropriate duration (number of university credits for each discipline) and course units that are clearly designed in order to achieve specific expertise. Physiology and biochemistry are academic disciplines mostly involved in teaching fundamentals of human nutrition, while the discipline of sciences of applied nutrition and dietetics more strictly focuses on nutrition and diet in the general population and at-risk groups, as well as on clinical nutrition. Depending on the type of degree, other academic disciplines that may significantly contribute to education in human nutrition are internal medicine (and its subspecialties), hygiene, endocrinology, food technologies, food chemistry, commodity science, and so forth.

Special attention must be paid to the education in human nutrition of physicians and other health professionals. For instance, in the degree of medicine there should be at least one unit concerning the fundamentals of human nutrition and another one on applied nutrition and clinical nutrition are expected. For some professional profiles a supervised training in clinical nutrition is mandatory.

The different types of graduates to some extent share a number of nutritional competencies and job opportunities. Indeed, graduates with different nutritional expertise can usefully collaborate in either the clinical or nonclinical setting. Nutrition can serve as a model for the type of interprofessional education that is needed to a broad range of health care professionals to meet today's health care needs.

Due to the educational organization of the Italian university System, curricular changes are proposed and implemented by the university departments, which supervise the different courses. The availability of shared documents on education in human nutrition (especially if focused on specific areas) and the interaction between nutrition societies and colleges of academic disciplines may help reaching changes at a local level. It appears much more difficult to modify the national regulation on university courses.

University education should carefully consider current regulations concerning professional profiles, in order to better collaborate with the corresponding professional orders.

Expertise in human nutrition must undergo continuous updating and retraining programs. The specialisations in nutritional sciences, masters, and advanced training courses are of great relevance. For the nonuniversity education it is important to mention the continuing medical education, CME.

The labour market should be stimulated to examine graduates' curriculum vitae taking into consideration not only legal qualifications but also knowledge, skills, and competencies which have been actually obtained.
The purpose of this position paper is to provide some general principles and suggestions to be considered for setting specific recommendations related to education in human nutrition within the different degrees. As stated in Introduction, however, further documents are needed to define in detail the indications for each considered degree with respect to format, learning objectives, and learning outcomes and to identify the curricular changes that could be implemented to provide a model for the type of interprofessional education that is needed to equip a broad range of health care professionals to meet today's health care needs.

\section{Conflict of Interests}

The authors declare that there is no conflict of interests regarding the publication of this paper.

\section{Acknowledgment}

This document was reviewed and approved by the Executive Board of the Italian Society of Human Nutrition (SINU).

\section{References}

[1] QTI, Qualification Framework for the Higher Education, http://www.quadrodeititoli.it.

[2] Bologna Process, European Higher Education Area, http:// www.ehea.info/.

[3] EQF, European Qualification Framework for lifelong learning, https://ec.europa.eu/ploteus/content/descriptors-page.

[4] Ministerial Decree, "Determination of classes of first-cycle degrees," Official Gazette of the Italian Republic no. 153, 2007.

[5] Ministerial Decree, "Determination of classes of second-cycle degrees," Official Gazette of the Italian Republic no. 155 of July 6th, 2007, and -OG no. 122 of May 28th, 2009, 2007.

[6] Ministerial Decree dated February 19th, 2009. Determination of classes of health profession degrees, Official Gazette of the Italian Republic, no. 119 of May 25th, 2009.

[7] Ministerial Decree, "Determination of classes of second-cycle health profession degrees," Official Gazette of the Italian Republic no. 122, 2009.

[8] P. M. Kris-Etherton, S. R. Akabas, P. Douglas et al., "Nutrition competencies in health professionals' education and training: a new paradigm," Advances in Nutrition, vol. 6, pp. 83-87, 2015.

[9] R. F. Kushner, L. Van Horn, C. L. Rock et al., "Nutrition education in medical school: a time of opportunity, American Journal of Clinical Nutrition, vol. 99, no. 5, supplement, pp. 1167S-1173S, 2014.

[10] C. M. Lenders, D. D. Deen, B. Bistrian et al., "Residency and specialties training in nutrition: a call for action," The American Journal of Clinical Nutrition, vol. 99, no. 5, supplement, pp. 1174S-1183S, 2014.

[11] L. Ball, J. Crowley, C. Laur, M. Rajput-Ray, S. Gillam, and S. Ray, "Nutrition in medical education: reflections from an initiative at the University of Cambridge," Journal of Multidisciplinary Healthcare, vol. 7, pp. 209-215, 2014.

[12] S. Ray, C. Laur, P. Douglas et al., "Nutrition education and leadership for improved clinical outcomes: training and supporting junior doctors to run 'nutrition awareness weeks' in 
three NHS hospitals across England," BMC Medical Education, vol. 14, article 109, 2014.

[13] P. M. Kris-Etherton, S. R. Akabas, C. W. Bales et al., “The need to advance nutrition education in the training of health care professionals and recommended research to evaluate implementation and effectiveness," The American Journal of Clinical Nutrition, vol. 99, no. 5, pp. 1153S-1166S, 2014.

[14] H. Cena, C. Roggi, L. Lucchin, and G. Turconi, "Health nutrition practice in Italy," Nutrition Reviews, vol. 68, no. 9, pp. 556563,2010 

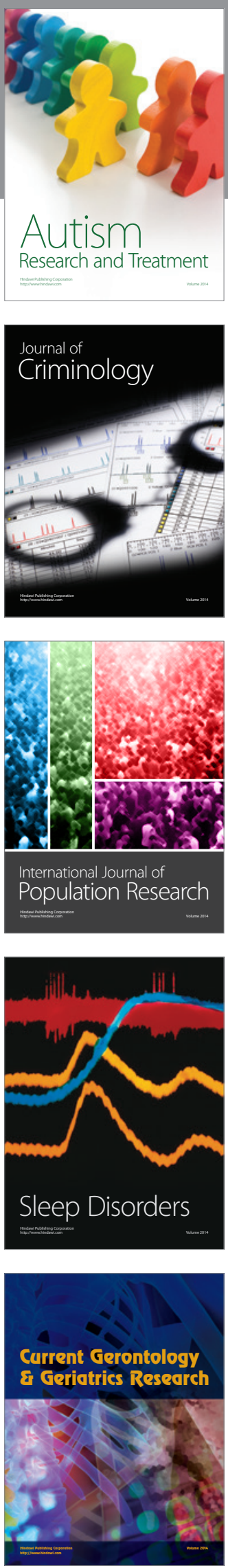
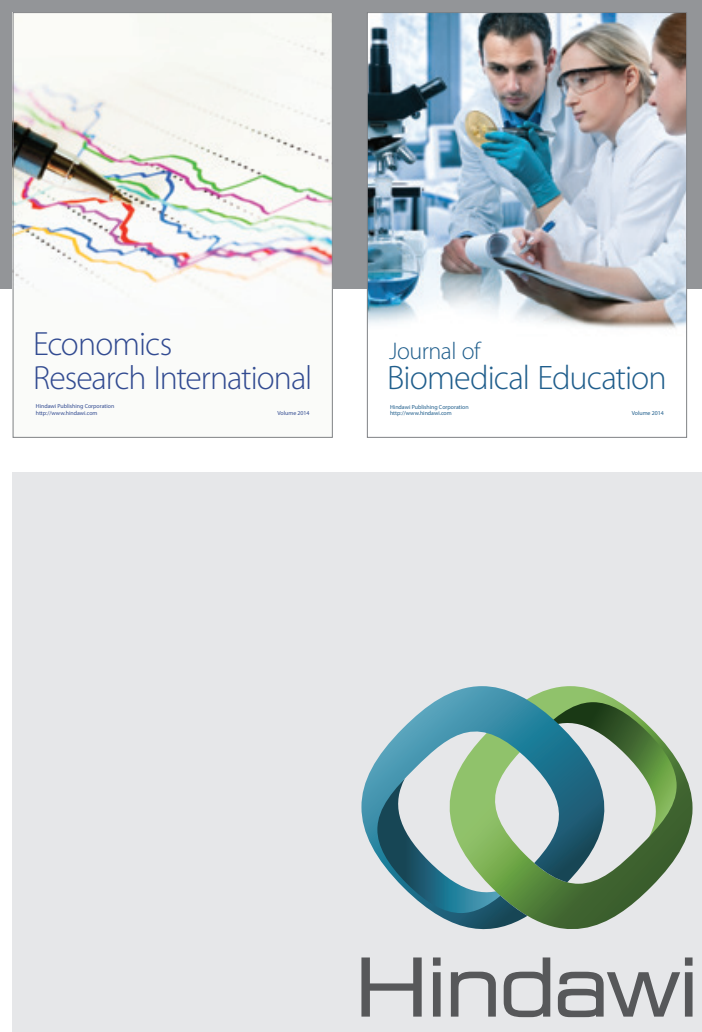

Submit your manuscripts at

http://www.hindawi.com
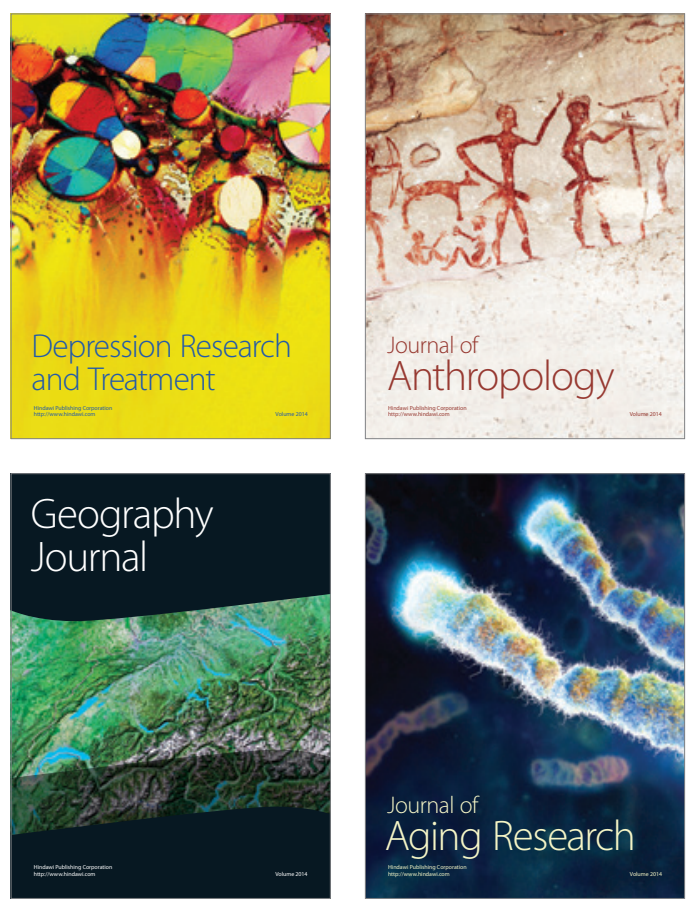
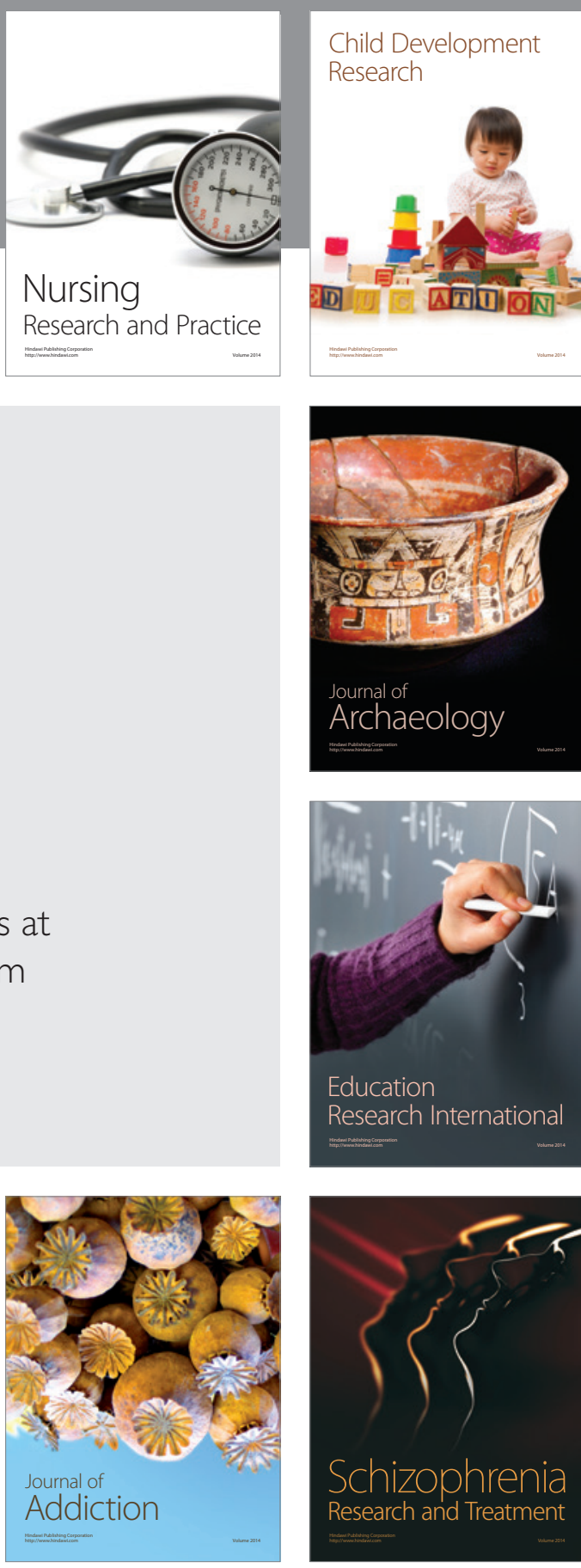

(D)
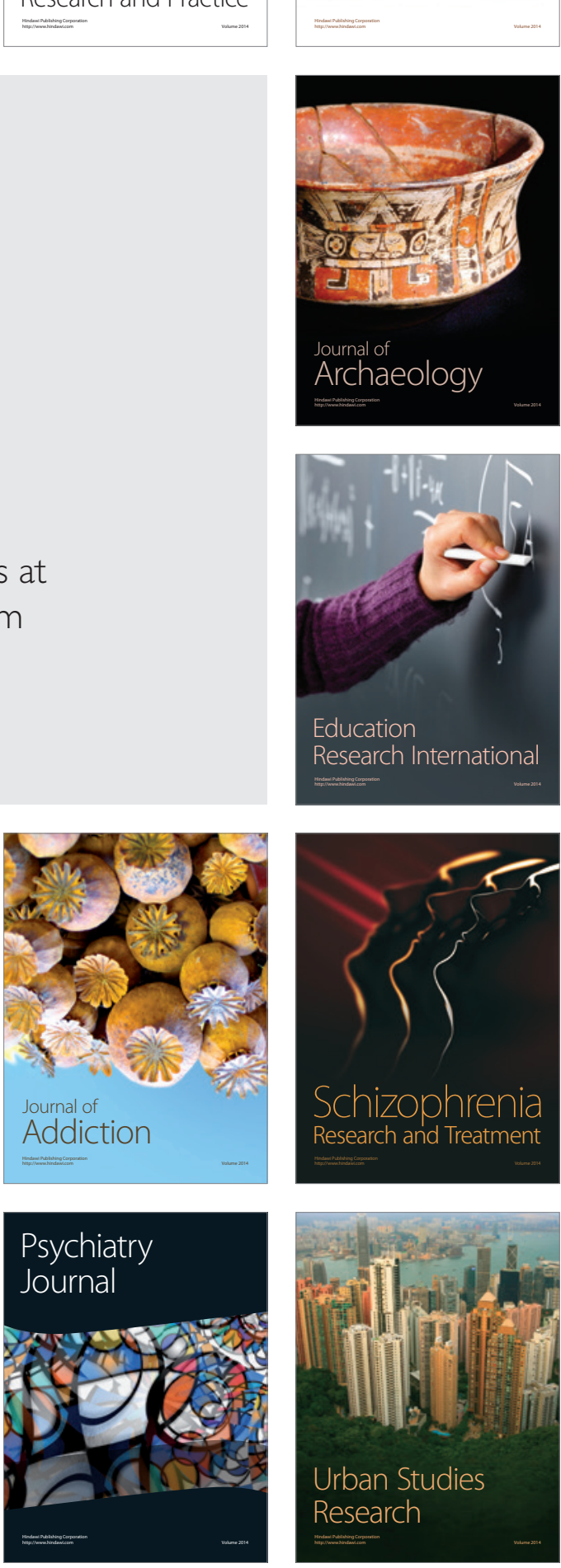